the size of the oxygen anion itself is not necessarily definite. The effective size of the oxygen anion may depend on the charge of neighbouring cation, the pressure and the temperature, but is generally considered to be 1.32 or $1.40 \AA$. The ideal sphere size for a co-ordination number of eight should then be $0.96 \AA$ or $1.02 \AA$. In spite of un. certainties in the size of the oxygen anion and those of the lanthanide cations (Table 1), it seems reasonable to speculate that the position of the break in the inflexional type of lanthanide pattern can be related to an ideal cation size for eight-fold co-ordination. This suggests that the inflexion is caused by the structure of the anion silicate network rather than by the presence of calcium cations, although the structure of minerals does depend on their chemical content of metallic cations. This interpretation also explains the more or less distinct discontinuity between the monotonic and inflexional patterns.

The monotonic lanthanide pattern is then interpreted as an indication of the absence of eight-fold co-ordination sites in the crystals, and the occupation by lanthanides of sites which were mainly of six-fold co-ordination, and were predominantly occupied by magnesium and ferrous iron. Akimasa Masuda

Goddard Space Flight Center,

Greenbelt, Maryland.

${ }^{1}$ Haskin, L. A., and Frey, F. A., Science, 152, 299 (1966).

${ }^{3}$ Masuda, A., and Matsui, Y., Geochim. Cosmochim. Acta, 30, 239 (1966).

${ }^{3}$ Masuda, A., Nature, 205, 971 (1965).

4 Masuda, A., Tectonophysics, 2, 299 (1965).

s Coryell, C. D., Chase, J. W., and Winchester, J. W., J. Geophys. Res., 68, $559(1963)$.

- Masuda, A., Nature, 205, 1098 (1965).

Goldschmidt, V. M., Skrifter Norske Videnskaps-Akad., Oslo, I: Math.Naturv. Kl., No. 2 (1926).

Ahrens, L. H., Geochim. Cosmochim. Acta, 2, 155 (1952).

- Mason, B., Principles of Geochemistry (John Wiley, New York, 1960).

${ }^{10}$ Schmitt, R. A., Smith, R. H., Lasch, J. E., Mosen, A. W., Olehy, D. A., and Vasilevskis, J., Geochim. Cosmochim. Acta, 27, 577 (1963).

\section{Nature of Ultra-violet Absorption of Sea Water}

IT has already been suggested that ultra-violet absorption of natural water is a useful index of water quality ${ }^{1-3}$. Armstrong and Boalch ${ }^{4}$ showed that the ultra-violet absorption of sea water is about twice that of a solution containing the same concentration of inorganic salts, and they attributed the difference to the presence of organic matter. They also recognized that absorption by nitrate is likely to be important in deep water. The nature of

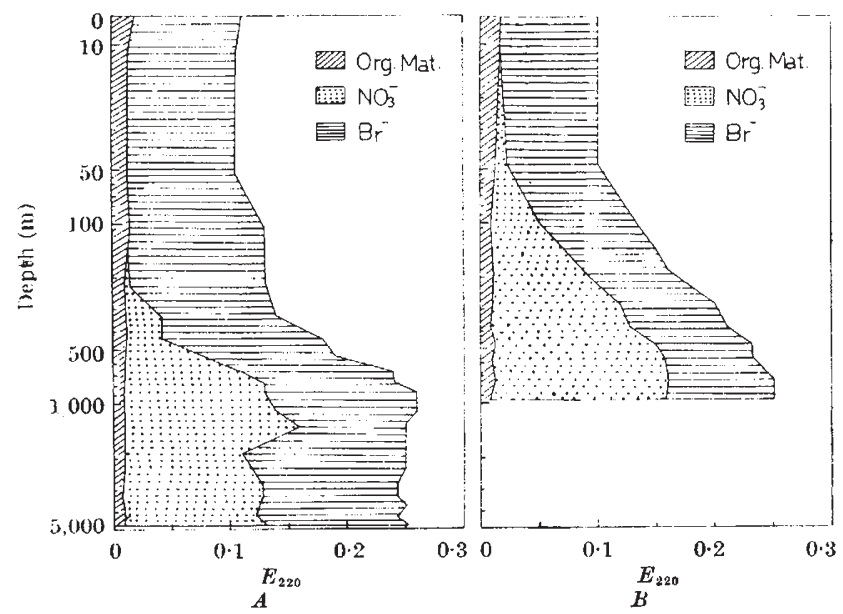

Fig. 1. Absorbance of sea water. $A$, Western North Pacific $\left(28^{\circ} 00^{\prime} \mathrm{N}\right.$. $\left.135^{\circ} 55^{\prime} \mathrm{E} ., 5,050 \mathrm{~m}\right) ; B$, Sagami Nada $\left(34^{\circ} 26^{\prime} \mathrm{N}\right.$., $\left.139^{\circ} 40^{\prime} \mathrm{E} ., 1,120 \mathrm{~m}\right)$.' ultra-violet absorption of sea water, however, has not been investigated in detail until now.

Samples of sea water from the western North Pacific and Sagami Nada were collected during June and July, 1966. They were filtered through $H A$-type 'Millipore' filters and stored in the cold. Ultra-violet absorption between 210 and 300 mil was measured with a cuvette $1 \mathrm{~cm}$ across in a photoelectric photometer; distilled water was used as the reference. The absorption was expressed in terms of the absorbance coefficient $(E)$. Dissolved organic carbon was determined by Menzel's method ${ }^{5}$.

Absorption increases with depth but dissolved organic earbon decreases with depth. Analogy with lake water suggests that organic matter (which is usually in the form of fulvic acid or related substances) in sea water has the following relation, $E_{220}$ (absorbance)/organic carbon $(\mathrm{mg} / \mathrm{l})=$.0.02 . From this rolation, absorbance at 220 $\mathrm{m} \mu$ by organic matter was estimated. Nitrato absorbs light in the short ultra-violet range below $230 \mathrm{mu}$. The concentration of nitrate, which is less than $0.10 \mu \mathrm{g}$ atom nitrate-nitrogen/l. in surface water, increases with depth. The greatest concentration amounts to about $40 \mu \mathrm{g}$ atom nitrate-nitrogen/1., the absorbance of which is equivalent to 0.15 at $220 \mathrm{~m} \mu$. Bromide has a very similar absorption spectrum to that of sea water which is free from organic matter and nitrate. The concentration of bromine in sea water is nearly constant and amounts to $67 \mathrm{mg}$ bromine/l. (compare with 19 parts per thousand of chlorine); the absorbance of bromide is 0.11 at $220 \mathrm{~m} \mu$. Absorption by bromide would account for the absorption. not attributed to organic matter and nitrate. Strong absorption of sea water at less than $230 \mathrm{~m} \mu$ disappears completely on addition of concentrated sulphuric acicl to sea water in the proportion of $1: 1$ by volume. Absorption by bromide also disappears under these conditions. Fig. I shows the absorbance of ultra-violet light.

The absorption of ultra-violet between 210 and 230 m $\mu$ by sea water can thus be attributed almost entirely to organic matter, nitrate and bromide, as shown in Fig. 2 . N. OGURA IT. HANYA

Department of Chemistry, Faculty of Sciener.

Tokyo Metropolitan University,

Setagaya-ku, Tokyo, Japan.

Hanya, T., and Ogura, N., proe. Interm. Meetioy in Milun, ltaly (1962); Adv. Org. Geochem., 447 (Pergamon Press, 1964).

2 Ogura, N., J. Chem. Soc. Japan, 86, 1282 (1965); ihid., 86, 1286 (196i)),

${ }^{3}$ Ogura, N., J. Oceanom. Soc. Japan, 21, 237 (1965).

4Armstrong, F. A. J., and Boalch, (x. T., J. Mar. Biol. Assor. I. K.. 41, $591(1961)$

'Menzel, D. W., and Vacraro, R. F., Limnol. Oceanour.. 9. 138 (1964). 